\title{
OUTRO OLHAR SOBRE MARIANA NO SÉCULO XIX
}

\author{
Sônia Maria de Magalhães*
}

\begin{abstract}
Resumo
Este artigo contribui para desmitificar aquela imagem típica de destruição natural e esgotamento aurífero da região de Mariana, antigo centro minerador que, ao contrário do que se pensava, abrigava enormes possibilidades de expansão econômica, abrindo-se a novos interesses e consolidando-se no início do século XIX.
\end{abstract}

Palavras-chave: alimentação; consumo; sociedade; economia; produção.

Estando a cidade de Mariana encostada a quinhentos pés abaixo de Vila Rica, e, além disso cercada de elevados montes, é ela confinada e quente...O abastecimento de água é farto, auxiliando grandemente no cultivo de muitos belos jardins...a situação deles não impede exibir uma grande variedade de frutos e flores. Para além deles estendem-se lindas paisagens verdejantes, em meio às quais corre o rio, como um fio de prata; e em redor fica um anfiteatro de montanhas, enfeixando e protegendo tudo. Há no lugar um insólito ar de felicidade, que me sinto propenso a atribuir à relativa ausência de espírito daninho das minas.

Jonh Luccock.

(Notas sobre o Rio de Janeiro e partes meridionais do Brasil.)

Somente no último quartel do século XVII, como resultado das descobertas realizadas pelas bandeiras paulistas, inicia-se a exploração

\footnotetext{
* Mestre em História pela UNESP-Franca. Professora do Departamento de História da FECLITA-Goiás.
} 
do ouro em Minas Gerais. E a região de Mariana surge dessas primeiras explorações auríferas quando os bandeirantes de Miguel Garcia e do Coronel Salvador Furtado descobriram grandes riquezas nas águas demasiadamente frias do Ribeirão do Carmo. Esta região compõe atualmente a área que se denomina Zona Metalúrgica-Mantiqueira, e o conjunto principal de montanhas da região chama-se Mantiqueira/ Espinhaço. A Serra do Espinhaço separa as águas da bacia do Rio Doce das do São Francisco. Suas correntes seguem até Ouro Preto; aquelas que seguem o caminho da cidade de Mariana recebem o nome de Ribeirão do Carmo.

Os primeiros veios auríferos descobertos na região foram nesse ribeirão, e em pouco tempo, ao longo do seu curso surgiu o primeiro arraial, que recebeu o mesmo nome. Segundo Salomão de Vasconcelos, Salvador e sua comitiva apossaram-se do ribeirão, dividindo as primeiras lavras e erguendo algumas cabanas ao longo das suas margens, formando o núcleo primitivo denominado Mata-Cavalos. Em 1701, o Ribeirão do Carmo já contava com vários arraiais, que se constituíam em torno do serviço de mineração.

A euforia do ouro - provocada pela possibilidade de enriquecimento rápido - fez com que um enorme contigente humano migrasse para essa área: "das cidades, vilas, recôncavos e sertões, vão brancos, pardos e pretos e muitos índios e toda a condição de pessoas (Lima Júnior, 1978)." Entorpecidos pelo esplendor do ouro, os primeiros mineradores descuidaram da questão mais imprescindível para a sobrevivência humana: a alimentação. Assim, já nos anos de 1697-1698, houve a primeira dispersão dos mineiros para o mato em decorrência da fome que assolou esse lugar, fato que se repetiria entre 1701 e 1702 .

Esta carência de gêneros predominou, principalmente, nos primórdios da colonização, com uma leva de aventureiros que se dirigiu para a região, determinando um rápido e desordenado povoamento. Nos primeiros anos, quase ninguém se preocupou em semear grãos, pois era mais fácil comprar mantimentos de fora do que desviar os escravos das catas para as plantações. Assim, o custo dos gêneros indispensáveis à sobrevivência alcançaram cifras exorbitantes. O cenário mineiro nesse período não poderia ser mais desolador: muitos homens que trabalhavam nas minas "andavam apilados e hidrópicos, todos em geral com pernas e cores de defuntos; apetecia-se comer terra e muitos o faziam" (Abreu, 
1976, p. 143). Nesses primeiros anos da colonização do território mineiro, a situação tornou-se calamitosa e os habitantes do Ribeirão do Carmo tiveram uma alarmante carência de víveres. E para agravar ainda mais a situação, uma violenta epidemia de bexigas devastou os arraiais (Lima Júnior, 1978). O único jeito foi fugir para os matos à procura de caça, mel, frutas e até de bichinhos repugnantes. Um anônimo acentua a fome nessa região nos primeiros anos da sua história.

Era tal a falta de mantimentos que se vendia no Ribeirão um alqueire de milho por 20 oitavas e de farinha por 32, o de feijão por 32; uma galinha por 12 oitavas, um cachorrinho ou gatinho por 32; uma vara de fumo 5 oitavas e um prato pequeno de estanho cheio de sal por 8. E tudo o mais a este respeito por cuja causa e fome morreu muito gentio, tapanhunos e carijós, por comerem bichos de taquara, que para os comer é necessário estar um tacho no fogo bem quente e aliás vão botando os que estão vivos logo bolem com a quentura que são os bons e se come algum que esteja morto é veneno refinado (Lima Júnior, 1978, p. 201).

Nas primeiras décadas do povoamento das Gerais, como não havia um interesse maior por parte da população e nem da Metrópole voltado para as atividades agropecuárias, os mineiros tiveram de buscar mercados abastecedores para atender às necessidades básicas da sua população. Esses mercados eram os de São Paulo, Bahia e Rio de Janeiro, que atenderam a essa demanda, oferecendo todos os tipos de produtos para a subsistência, além de artigos de luxo destinados à população mais abastada. Os gêneros consistiam, principalmente, em comestíveis importados do Reino, equipamentos para a mineração, além de utilidades domésticas.

As condições de vida nas Minas nos primórdios da colonização, mesmo contando com o apoio desses três mercados abastecedores, eram extremamente precárias. Em certas ocasiões, essa região deixava de contar com o abastecimento regular desses mercados por causa das péssimas condições de transportes e dos caminhos, pioradas por enchentes. Foi o que aconteceu nos anos de 1700-1701, quando Minas ficou isolada, acarretando um gravíssimo estado de fome. Se a fome dos anos anteriores tinha sido grave, a daqueles anos alcançou níveis extremos. O resultado não poderia ser outro: dezenas de pessoas morreram por inanição e as 
perdas com os escravos foram incalculáveis (Lima Júnior, 1978). Para Zemella, essas crises se verificaram inicialmente por não haver ainda sido sistematizado o sistema dos fornecimentos. Em outras ocasiōes houve apenas a escassez de víveres, e não a sua falta absoluta. Os preços dos alimentos chegaram a níveis absurdos e, assim, a morte por inanição atingia apenas os miseráveis e a escravaria. As graves crises de abastecimento e de fome não ficaram restritas aos anos de 1697-1698 e 1700-1701. Em 1713, em Pitangui, houve um novo surto de fome. Assim, a fome e a carestia dos gêneros constituíram os dois traços preponderantes daquele período. Mesmo com a regularização do fornecimento de gêneros que entravam principalmente pelo São Francisco e Rio de Janeiro, algumas vilas continuaram sofrendo carências. A explicação para a falta constante de gêneros de subsistência está relacionada à especulação das mercadorias feita pelos atravessadores. Eles compravam gêneros alimentícios dos tropeiros ou de agricultores para revendê-los mais tarde aos moradores das vilas e redondezas. A forma de especulação era a mais comum, ou seja, esses agentes estocavam as mercadorias para forçar a alta dos preços. Além do mais, os atravessadores costumavam também transportar produtos para outros mercados, procurando melhores ofertas (Chaves, 1995). Durante todo o século XVIII, as autoridades administrativas tentaram coibir a atuação desses agentes sem conseguir sucesso algum. Desse modo, mesmo havendo um abastecimento regular de gêneros, a fome continuava a amedrontar a população. O edital publicado na Vila de Nossa Senhora do Carmo, atual Mariana, em 1732, demonstra a situação vigente: "No morro de Mata-Cavalos e em outras partes, há grande falta de mantimentos para o sustento dos negros e ainda dos brancos" (Vasconcellos, 1994).

A escassez, somada à carestia dos alimentos, não abandonou totalmente a região, mesmo quando a agricultura passou a fazer parte definitivamente das unidades produtivas mineiras. A presença da fome no século XIX, na região de Mariana - precisamente no ano de 1830 pode ser demonstrada por meio do documento que segue:

Capitão João dos Santo França [?] Juiz de Paz do Presidio de São João Batista expondo a necessidade sumária por Edital o lugar da praça da Nova Matriz para vendagem de mantimentos por haver fome e resolveu que o senhor presidente expressa o Edital e Ofício necessário (AHCMM-Atas da Câmara-livro 206). 
Se por um lado a fome foi a grande inimiga dos primeiros mineiros que se estabeleceram ao longo do ribeirão do Carmo, ocasionando um breve despovoamento do arraial, por outro lado fez com que os mineiros se tornassem mais cuidadosos e previdentes. Além disso, a fuga para os matos em busca de alimentos acarretou o desbravamento em torno do ribeirão, e o estabelecimento de novos povoados e das primeiras unidades produtivas agrícolas na região. Segundo Diogo de Vasconcelos, nesse período se instalaram as mais antigas fazendas do Carmo, do Gualaxo do Norte e do Gualaxo do Sul -1697-1698 (Vasconcellos, 1974).

Nas primeiras décadas do século XVIII, a região do Carmo já abrigava uma imensa população e uma intensa vida comercial. Assim, por volta de 1711, o governador do território das Minas e de São Paulo elevou o Arraial do Ribeirão do Carmo à condição de vila. Também por meio desta mesma determinação régia, foram criadas: a vila de Sabará e a Vila Rica.

O território da Vila do Ribeirão do Carmo abrangia os sertões dos Rios Pomba, Muriaé e Doce, atingindo as fronteiras do Rio de Janeiro. Com a criação de novas vilas, os territórios de Sabará e de Vila Rica foram, ao longo do tempo, subdivididos enquanto o de Vila do Carmo permaneceu intacto. Por conseqüência, quando foram criadas as quatro comarcas mineiras em 1714, a Vila do Ribeirão do Carmo - que juntamente com a Vila Rica constituía a comarca do mesmo nome - passou a ter jurisdição muito maior do que Vila Rica. Além da Comarca de Vila Rica, foram criadas outras a seguir: a do Rio das Mortes, composta por São João Del Rei, Queluz, São Carlos de Jacuí, Santa Maria de Baependi, Campanha, Barbacena e Tamanduá; a do Serro Frio, integrada pela Vila do Príncipe e Fanado, e a de Sabará, constituída por Sabará, Caeté, Pitangui e Paracatu. Em 1815, uma nova comarca seria criada: a de Paracatu do Príncipe (Lewkowicz, 1992).

O território da Vila do Carmo ocupava uma área de $50.000 \mathrm{~km}^{2}$, permanecendo nessas condições até 1831 , quando foi criado o município do Rio Pomba (Lewkowicz, 1992). A região em estudo apresentava um quadro natural diverso

possuindo um relevo acidentado, uma diversidade geológica, vegetação tropical exuberante, clima úmido e ameno nas áreas mais altas e quente nos locais de menor altitude, uma teia de riachos e rios com águas límpidas e profundas (Andrade, 1994, p. 247). 
Essas características naturais ampliavam as possibilidades de expansão econômica, abrigando importantes áreas mineratórias, trechos agrícolas e lugares ainda intocados pelo homem.

Vários distritos que compunham a região de Mariana no século XIX surgiram a partir do terceiro quartel do século XVIII. Percebe-se, assim, que essa região possuía uma imensa potencialidade de expansão territorial e uma enorme fronteira aberta. Por volta de 1780, quando a extração aurífera se tornou mais difícil e dispendiosa, a população embrenhou-se cada vez mais naquele território, buscando áreas favoráveis para a intensificação das atividades agropecuárias (Almeida, 1994, p. 52). A diversificação econômica, entretanto, já era uma realidade desde o início das atividades mineratórias. Houve pessoas que preferiram investir em atividades agropastoris, comerciais ou artesanais, a aventurarse na faiscação e garimpagem. Carrato, analisando as "Devassas Eclesiásticas de Mariana”, demonstra que, na primeira metade do século XVIII, a maioria da população encontrava-se ocupada com as atividades agrícolas (Carrato, 1968). Reforçando as idéias de Carrato, Carlos Magno Guimarães evidencia a importância da agricultura mercantil de subsistência vinculada ao abastecimento interno desde as primeiras décadas do povoamento mineiro (Guimarães, 1987). Essa vinculação pode ser confirmada na concessão de cartas de sesmarias. Vejamos, como exemplo, a carta de sesmaria concedida a Leonardo Francisco Palhano em 1737:

Queria povoar de gados tendo já principiado a cultivá-lo e se chama sítio de São Leonardo, que parte do nascente com a fazenda do Capitão João Jorge Rangel...e do poente com a estrada que vai de Pitangui para os Goiazes... (Guimarães, 1987, p. 98).

Inúmeras sesmarias foram concedidas visando à prática e ao desenvolvimento de atividades agropastoris. Observa-se uma atividade agrícola constante durante os anos setecentos em Minas Gerais. Desde o início da colonização do território mineiro houve uma tendência à diversificação econômica. José Joaquim da Rocha descreve, no final do século XVIII, a abundância na produção de hortaliças e frutas (couves, repolhos, cebolas, bananas, abacaxis, mamões, laranjas, pêssegos, marmelos, e mesmo café) em Mariana e Vila Rica. No entanto, Rocha tem o cuidado de considerar que se tratava de lavouras pequenas, 
importando das demais comarcas da capitania toucinho, milho, queijo, feijão, arroz e azeite (Paula, 1988). Os estudos citados acima contrariam a idéia de que em Minas, a primeira metade do século XVIII foi marcada pela opulência aurífera, e a segunda, pela miséria e decadência econômica, conforme apresenta a historiografia "tradicional". A região de Mariana, com certeza, não se enquadrava no painel traçado por essa historiografia, porquanto apresentava os elementos sociais e econômicos característicos da agricultura de subsistência no século XIX. Além disso, abrigava a maior população de pessoas livres e a segunda concentração de escravos de Minas Gerais, perdendo apenas para São João Del Rei. Com base nesses elementos, Carla Almeida descarta a periodização tradicional estabelecida para o contexto mineiro, e propõe uma nova periodização abrangendo os anos de 1750 a 1850. Almeida considera os anos de 1750 a 1770 como o período do auge da mineração; 1780 a 1810 seriam os anos que rumaram à auto-suficiência; de 1820 a 1850, Minas estabeleceuse com a economia mercantil de subsistência (Almeida, 1994).

O primeiro subperíodo é caracterizado por Carla Almeida como o do auge econômico, tendo-se em consideração a superação de 100 arrobas anuais de ouro no decênio de 1750. Almeida observa que houve um crescimento das unidades produtivas de mineração entre 1760 e 1770, que de $40 \%$ em 1760 , passou a $87,5 \%$ do total das unidades produtivas em 1770. Essa efervescência mineratória pode ter sido possível graças ao incentivo governamental de ocupação de novas áreas em busca de novos veios auríferos.

Quanto ao segundo subperíodo - 1780 a 1810 -, a mineração cedeu espaço cada vez maior para as atividades agropecuárias. Entre $1750 \mathrm{e} 1770$, as unidades produtivas mineradoras representavam $61,9 \%$, e no segundo período apenas $34,2 \%$. Nesse momento, porém, essas unidades produtivas agropecuárias visavam ao autoconsumo, negociando apenas supostos excedentes.

Finalmente no terceiro subperíodo - 1820 a 1850 -, o excedente da produção agropecuária passou cada vez mais a ser endereçado a mercados mais distantes. Segundo Almeida, outro elemento que reforça essa idéia relaciona-se ao aumento de inventários com a presença de tropas que, de $3 \%$ no primeiro período passou para $17 \%$ entre 1780 1810 , e alcançou $18 \%$ no final desse período. Ademais, ela observa o crescimento do rebanho bovino, sugerindo que sua produção interessava 
cada vez mais ao mercado. O quadro a seguir revela maiores detalhes sobre o resultado dos estudos de Almeida.

Quadro 1 - Monte-mor médio em mil réis por tipo de Unidade Produtiva (U.P.) e subperíodos e número médio de escravos em Mariana

\begin{tabular}{|l|r|c|c|c|c|c|}
\hline \multicolumn{1}{|c|}{ Tipos de U.P } & \multicolumn{2}{|c|}{$1750-1770$} & \multicolumn{2}{c|}{$1780-1810$} & \multicolumn{2}{c|}{$1820-1850$} \\
\hline & $\begin{array}{c}\text { monte-mor } \\
\text { médio de } \\
\text { escravos }\end{array}$ & $\begin{array}{c}\mathrm{n}^{2} \text { médio } \\
\text { de } \\
\text { escravos }\end{array}$ & $\begin{array}{c}\text { monte-mor } \\
\text { médio de } \\
\text { escravos }\end{array}$ & $\begin{array}{c}\mathrm{n}^{2} \text { médio } \\
\text { de } \\
\text { escravos }\end{array}$ & $\begin{array}{c}\text { monte-mor } \\
\text { médio de } \\
\text { escravos }\end{array}$ & $\begin{array}{c}\mathrm{n}^{2} \text { médio } \\
\text { de } \\
\text { escravos }\end{array}$ \\
\hline Pecuária & 359,854 & 2 & 758,370 & 6 & $1.178,045$ & 2 \\
\hline Agrícola & $1.847,134$ & 6 & 907,930 & 7 & $2.669,687$ & 7 \\
\hline Mineradora & $2.153,671$ & 14 & $3.838,885$ & 8 & $2.131,353$ & 4 \\
\hline Agropecuária & $3.330,087$ & 20 & $2.325,291$ & 9 & $5.209,315$ & 11 \\
\hline $\begin{array}{l}\text { Agrícola- } \\
\text { mineradora }\end{array}$ & $3.998,013$ & 20 & $4.050,573$ & 19 & $9.017,085$ & 14 \\
\hline $\begin{array}{l}\text { Agropecuária- } \\
\text { mineradora }\end{array}$ & $5.555,521$ & 24 & $3.739,912$ & 20 & $8.028,743$ & 15 \\
\hline
\end{tabular}

Transcrito de: ALMEIDA, Carla Maria Carvalho de. Alteraçōes nas Unidades Produtivas Mineiras: Mariana - 1750-1850.

A análise de cerca de 300 inventários post-mortem da região de Mariana, correspondendo aos séculos XVIII e XIX, suplementam as idéias de Carrato, Guimarães e Carla Almeida. Os dados ali encontrados contribuem para demonstrar a presença das atividades agropecuárias convivendo com a mineração em seus períodos iniciais, e intensificandose na medida em que diminuíam os trabalhos mineratórios.

A diversificação da economia mineira pode ser observada nas descrições de algumas propriedades rurais da região. Uma delas, na paragem de Pissarrão, freguesia de São Sebastião, possuía um sítio de roça com capoeiras de 30 alqueires e restingas de mato virgem. Abrigava ainda uma casa de vivenda e senzalas cobertas de telhas, e no quintal, árvores de espinho e bananal. Um moinho corrente e moente integrava as edificações dessa propriedade (ACSM, 1 Ofício, Cód. 156, Auto 3.261). Uma outra, na Barra do Bacalhau, possuía uma roça e um sítio. A roça era formada por terras de plantação, capoeiras, matos virgens e terras minerais, águas, casas de vivenda, paiol e senzalas. O sítio, por sua vez, abrigava terras inferiores de plantação, com casas de vivenda e 
milho já plantado, perfazendo posteriormente o equivalente a dez alqueires (ACSM. 2 Ofício, Cód 76, Auto 1.646). A diversidade de propriedades voltadas ao mesmo tempo às atividades mineratórias e agropecuárias não confirma apenas a potencialidade do mercado local; demonstra que essa pluralidade de atividades produtivas não ficou restrita às camadas mais pobres daquele núcleo social, inserido num processo de concentração de riqueza (Silveira, 1997).

A região onde está localizada Mariana - na serra Mantiqueira/ Espinhaço - abrigava nos vales montanhosos uma variada formação vegetal, constituída por extensas matas virgens e capoeiras ou capões. A mata denominada capoeira era resultado do corte e da queimada de uma floresta virgem, após algumas plantações consecutivas. Os efeitos da queimada sobre o solo acarretavam naturalmente, uma menor fertilidade em relação às matas virgens situadas nas encostas das montanhas, onde se encontravam também diversas nascentes de rios e riachos. As chuvas que caíam em abundância, somadas à umidade das encostas e dos vales, propiciavam a formação de florestas. Foi nestas florestas, junto às matas detentoras de terras extremamente férteis, que os primeiros lavradores edificaram suas moradas e fizeram suas plantações (Andrade, 1994). Carrara enfatiza duas paisagens rurais distintas em Minas Gerais: os sítios, que se localizavam nas áreas mineratórias ou ao longo das principais estradas e caminhos e outra sertaneja, fazendo parte das fazendas. No setor agrícola da região de Mariana havia dois grupos econômico-sociais preponderantes, segundo Andrade: os roceiros e os fazendeiros. Essa região teve na primitiva agricultura de roça, aberta normalmente na mata virgem, a sua unidade produtiva predominante. A policultura do milho e do feijão era a mais praticada. A criação de pequenos animais, como porcos e galinhas complementava a subsistência dos roceiros.

A desigualdade social e econômica entre os roceiros e os fazendeiros encontrava-se essencialmente na posse de escravos. Normalmente os roceiros eram pequenos ou médios proprietários de escravos, podendo também não possuir escravo algum, o que resultava em unidades agrícolas de menor porte e potencial produtivo. $\mathrm{O}$ trabalho escravo coexistia com o livre, porém era secundário e complementar. Assim, as relações de parentesco, a participação da família composta pelo roceiro, a mulher e os filhos eram fundamentais no processo produtivo 
doméstico, principalmente na época dos grandes trabalhos agrícolas, como a derrubada e queima da mata. Os fazendeiros, ao contrário, eram dirigentes de unidades produtivas maiores, possuindo onze ou mais escravos, o que resultava na grande produção agrícola e pecuária. Os fazendeiros mais prósperos da região de Mariana eram os que produziam aguardente, rapadura e/ou açúcar, segundo Andrade.

O inventário de dona Maria José da Fonseca, casada com o capitão João de Lana, possibilita-nos ter uma melhor visão das unidades produtivas estabelecidas naquela região. O casal morava em Arrepiados, freguesia de Furquim, e possuía, entre os bens de raiz, uma morada de casas térreas cobertas de telhas, quintal, bananeiras, árvores de espinho e café. Essa propriedade abrigava também um moinho corrente e moente. Havia também terras de cultura no córrego Santo Antônio da Pedra Redonda, com 20 datas minerais a parte central do córrego, com capoeiras de 40 alqueires e paiol coberto de telhas. Em Vila Rica, o casal possuía uma morada de casas de sobrado, localizada na Rua Direita. Dentre os seus bens encontravam-se um porco cevado, dez porcos "criando no terreiro", seis cabeças de gado vacum, uma besta denominada "Garota", uma outra besta com sua cangalha, um cavalo baio e oito escravos. Estavam já plantados dois alqueires de milho e um alqueire e uma quarta de feijão. A presença de instrumentos agrícolas sustentam ainda mais a idéia da prática dessas atividades rurais: três foices, seis machados, duas enxadas, um martelo, um almocafre e uma torquês (ACSM. $2^{\circ}$ Ofício, Cód. 36, Auto 833).

O sistema de roças com pousio longo, geralmente de 20 a 30 anos, foi o mais viável para o tipo de agricultura que se estabeleceu na região de Mariana, pois esta prática dispensava muitos braços nos trabalhos agrícolas, além de não exigirem muitos equipamentos. As técnicas agrícolas eram as mesmas aplicadas por todo o Brasil, consistindo em:

Derrubar matas e capoeiras com machados, aproveitar troncos e galhos como lenha, depois de secos, atear fogo à área desmatada, destoucar com enxadões e picaretas troncos e raízes, couvar a terra para receber as sementes, com enxadas e, com elas, limpar ervas e matos rasteiros (Meneses, 1997, p. 53). 
Apesar de esse sistema agrícola ter sido radicalmente criticado pelos viajantes estrangeiros que por aqui passaram, como Saint-Hilaire, Andrade acentua que houve extremo exagero sobre seus efeitos predatórios. Esse autor afirma que a tecnologia agrária utilizada (foices, machados, enxadas, cavadeiras e a ausência de fertilização adicional), aliada à intensidade da exploração desse tipo de cultivo, além de favorecer o desenvolvimento das plantas estimulava a capacidade de recuperação do solo - desde que não fosse utilizada intensamente -, o que por certo levaria à sua estagnação (Andrade, 1994).

Os instrumentos de trabalho utilizados nas unidades agrícolas permaneceram quase inalterados em todo o período estudado. Para Carla Almeida, em uma economia que dependia da incorporação constante de terras virgens, de mão-de-obra e de taxas elevadas de investimentos, não se observa o aumento da produção, mas apenas as condições para a manutenção do seu nível. Independentemente do potencial produtivo, nessas propriedades os investimentos mais significativos voltavam-se para a mão-de-obra escrava e para as terras que iriam constituir as roças.

Com a relativa diminuição da intensidade das atividades mineratórias, algumas localidades na região de Mariana continuaram minerando e vivendo dos seus rendimentos, mesmo no limiar do século XIX. A ocorrência de uma diversidade de atividades econômicas numa mesma região é bem acentuada nos estudos realizados por Eduardo Andrade na região de Mariana. Ele demonstra que o ritmo e a dinâmica socioeconômica dos anos oitocentos nessa região variaram muito. A localização geográfica e as condições ecológicas dos núcleos populacionais, o desgaste ambiental gerado pela intensa atividade mineradora e as condições econômicas da prática de atividades agropecuárias diferenciaram-se bastante. As freguesias de Furquim, São Caetano, Catas Altas de Mato Dentro e as povoações de Nossa Senhora dos Remédios e Antônio Pereira, que tinham a cidade de Mariana como núcleo político-administrativo, constituíram o espaço geográfico para as análises de Andrade. ${ }^{1}$

Dos núcleos populacionais considerados por Andrade, podem-se agrupar São Caetano, Furquim e Catas Altas na imagem indiscriminada dos recursos naturais. Em Catas Altas, porém, a destruição ambiental e o empobrecimento do solo foram mais intensos. No entanto, com a diminuição da exploração mineratória ocorreu uma considerável 
regeneração do ecossistema. As plantas florestais se renovaram, e mesmo as áreas de campos artificiais tornaram-se úteis para a prática da pecuária e da agricultura. A localização privilegiada dessa freguesia - nas margens da "estrada real" que ligava a capital da província de Vila Rica à comarca de Serro Frio - beneficiou as atividades comerciais dos habitantes próximos da estrada. Catas Altas, dessa forma, caracterizava-se pela produção agropecuária, pelas atividades comerciais e ainda pelas mineradoras.

Nos primórdios do século XIX, a população de Nossa Senhora dos Remédios tinha como atividade econômica principal as práticas agrícolas; ao que tudo indica, a mineração não foi uma atividade relevante nessa localidade. Sua agricultura baseava-se no cultivo de gêneros básicos de subsistência, como o milho. Andrade considera a possibilidade do envolvimento dessa localidade nos fluxos comerciais regionais do Termo de Mariana e da Comarca de Barbacena, e inter-regionais com a Vila de Barbacena e a comarca de Rio das Mortes.

A transformação manufatureira da cana-de-açúcar foi a principal atividade da freguesia do Furquim, e contribuiu para a intensificação das práticas comerciais dos seus habitantes. Andrade acentua a disseminação dos engenhos e engenhocas na localidade, favorecendo o aumento do valor das propriedades agrícolas locais.

Quanto à localidade de Antônio Pereira, esta apresentava um núcleo populacional diferenciado dos demais. O subsolo dessa freguesia continuava, no início da primeira metade do século XIX, propício às lavras minerais, e seus moradores podiam viver, na medida do possível, do ouro extraído das águas dos rios e das encostas da serra. Assim, o universo socioeconômico de Antônio Pereira indica que a decadência da mineração deve ser analisada considerando-se outros aspectos.

De um modo geral, ao estudar as documentações e a literatura mais recente referentes às Minas setecentistas e oitocentistas, deparamonos com uma região que abrigava um imenso potencial econômico. As novas abordagens da economia mineira contribuem para desmitificar aquela imagem típica de destruição natural e esgotamento aurífero desse antigo centro minerador que, ao contrário do que se pensava, abrigava enormes possibilidades de expansão econômica, abrindo-se a novos interesses e consolidando-se no início do século XIX. Principalmente nas regiōes de Mariana e Vila Rica, que se tornaram alvos de mineradores 
e de outras pessoas interessadas principalmente nas práticas agropecuárias.

\begin{abstract}
This article contributes to dispel the myths surrounding that typical picture of natural destruction and exhaustion of gold of Mariana's region, old miner center which, on the contrary of was thought, sheltered large possibilities of economic expansion, opening itself to new interests and becoming solid in the beginning of $19^{\text {th }}$ century.
\end{abstract}

Key words: food; consume; society; economy; production.

\title{
Notas
}

1. A paróquia de São Caetano localizava-se na margem esquerda do Ribeirão do Carmo, ficando a três léguas da sede do seu termo, Mariana. A freguesia de Furquim situava-se no curso mais baixo desse ribeirão e foi fundada em 1706. Catas Altas do Mato Dentro localizava-se a sete léguas de Mariana, e já tinha existência efetiva desde 1710. Nossa Senhora dos Remédios formou-se a partir de uma capela em 1763. Este distrito pertenceu ao município de Mariana e à comarca de Vila Rica/Ouro Preto até as primeiras décadas do século XVIII. A localidade de Antônio Pereira estava a duas léguas a nordeste da sede do seu termo. Em 1720, a localidade de Antônio Pereira tornou-se paróquia. ANDRADE, op. cit., 1994.

\section{Referências Documentais}

Arquivo Histórico da Câmara Municipal de Mariana (AHCMM)

- Atas da Câmara de Mariana-Livro 206.

Arquivo da Casa Setecentista de Mariana (ACSM)

- Inventário do Cartório do 1ํofício. Códice 156. Auto 3.261.

- Inventário do Cartório do $2^{2}$ Ofício. Códice 76. Auto 1.646.

- Inventário do Cartório do 2ºfício. Códice 36. Auto 833. 


\section{Referências Bibliográficas}

ABREU, Capistrano de. Capítulos da História Colonial: 1500-1800. Os caminhos antigos e o povoamento do Brasil. Brasília: UnB, 1982. ALMEIDA, Carla Maria de. Alterações nas Unidades Produtivas Mineiras: Mariana - 1750-1850. Niterói, 1994. 220 p. Dissertação (Mestrado em História) - Universidade Federal Fluminense.

ANDRADE, Francisco Eduardo de. A enxada complexa: roceiros $e$ fazendeiros em Minas Gerais na primeira metade do século XIX. Belo Horizonte, 1994. 270 p. - Dissertação (Mestrado em História) - Universidade Federal de Minas Gerais.

CARRARA, Ângelo Alves. Agricultura e pecuária na Capitania de Minas Gerais (1674-1807). Rio de Janeiro, 1997. -Tese (Doutorado em História) - Universidade Federal do Rio de Janeiro.

CARRATO, José. Igreja, Iluminismo e Escolas Mineiras Coloniais. São Paulo: Nacional, 1968.

CASAL, Manuel Aires de. Corografia Brasílica ou Relação HistóricoGeográfica do Reino do Brasil. Belo Horizonte: Edusp/Itatiaia, 1976.

CHAVES, Cláudia Maria das Graças. Perfeitos negociantes: mercadores das Minas Setecentistas. Belo Horizonte,1995. 198 p. - Dissertação (Mestrado em História) - Universidade Federal de Minas Gerais.

GUIMARÃES, Carlos Magno e REIS, Liana. Agricultura e Caminhos de Minas (1700 -1750). Revista do Departamento de Histórial $U F M G$, Belo Horizonte, $\mathrm{n}^{\mathrm{Q}} 4$ 4, p. 85-99, 1987

LEWKOWICZ, Ida. Vida em família: caminhos da igualdade em Minas Gerais. (Séculos XVIII-XIX). São Paulo, 1992. - Tese (Doutorado em História) - Universidade de São Paulo.

LIMA JÚNIOR, Augusto de. A Capitania de Minas Gerais. Belo Horizonte: Edusp/Itatiaia, 1978.

PAULA, João Antônio de. O Prometeu no Sertão: Economia e Sociedade da Capitania das Minas dos Matos Gerais. São Paulo, 1988 - Tese (Doutorado em História) - Universidade de São Paulo.

VASCONCELOS, Diogo Pereira Ribeiro de. História Média de Minas Gerais. Belo Horizonte: Itatiaia/Edusp, 1974.

Breve descrição geográfica, física e política da capitania de Minas Gerais. Belo Horizonte: Fundação João Pinheiro, 1994. 